leg, to conform to its axis, and to be cut away so as to be extremely light, smooth and elastic; and when so constructed and applied, the limb may be raised from the bed and suddenly dropped without danger of displacement. Either of these splints, if properly applied, will hold the leg so firm that displacement and spasmodic contraction cannot occur, and consequently no counter-extension will be necessary beyond occasional adjustment by the hands of an assistant. Book-binder's board furnishes the material for an excellent splint for the lower leg. It is light, elastic, and can be applied with great facility. It adapts itself, when wet, with perfect accuracy, and has the property of retaining its form, and even in compound fractures it can be so applied as to prevent motion at the seat of fracture, and yet leave the wounded integuments free from pressure and open to view. Treated upon these principles, no counter-extension to the lower leg is necessary. It is difficult, indeed, to apply mechanical extension to fractures of the lower leg, without disturbing its axis; and if the cure is accomplished by aid of the doubleinclined plane, or by counter-extension, the leg will be too straight, and it is likely there will be more or less of angular direction in the fractured bones.

Such is the simple treatment I consider efficacious in fractures of the lower leg; but in the thigh, a somewhat modified plan of carrying out the same principle is required.

[To be continued.]

\title{
A CASE OF HYDROPHOBIA.
}

[Read before the Boston Society for Medical Observation, March 6, 185t, by CharLes D. Homans, M.D.]

[Communicated for the Boston Medical and Surgical Journal.]

J. W. H., of Charlestown, a lad 15 years of age, rather small in stature, with light hair, eyes and complexion, of good general health, but of a somewhat nervous temperainent, was bitten, Jan. 27 th, by a dog supposed to be mad, which was lying on the floor at the foot of the stairs of the house in which the lad resided. As he stooped to caress the animal, he was bitten by him in the calf of the left leg and about the right ear; he was bitten first in the ear, and afterwards, raising his foot to kick the animal, received the wound in the leg. Immediately after this happened, the lad hung down his head sullenly and slowly followed the dog, regardless of his mother's entreaties to return; this was totally unlike his usual habit. Two other persons were bitten at the same time; one a lad of 9 years, the other an Irishman who afterwards killed the dog. The wound of the man was slight and immediately cauterized, and neither of these persons have yet shown any signs of disease. On being spoken to on Thursday last, respecting the death of the boy with hydrophobia, the Irishman appeared morose and sullen, but said nothing.

The wounds of J. W. H. were bathed in laudanum and water, and healed up kindly, or at least scabbed over in forty-eight hours; without suppuration or much pain. Nothing was noticed in this lad out of the 
common way, save that he always appeared more "elated" than was natural to him, till Saturday evening, Feb. 25, when, on conversing with a lady, he fell suddenly asleep, and on awaking said he could not help it. On going to church Sunday, Feb. 26, he was noticed to shiver frequently, and complained of feeling cold; said there was a "catch in his breath" every few minutes. This continued, increasing in severity, attended with loss of appetite, inability to swallow liquids without suffering considerably, great restlessness and wakefulness. His mother made him swallow abour $3 \mathrm{jj}$. of infusion of senna on Sunday evening, which he immediately vomited, together with the food he had taken in the morning. He passed a sleepless night, and his sufferings having in no way abated on Monday, his mother came to the city and requested me to visit him.

Monday, Feb. 27, 1, P.M.-On entering room found patient lying in bed, with a rather hot, dry skin, tongue dry, slightly furred, papillæ being very distinct; eyes widely open, with a fixed vacant expression; countenance anxious, frightened; pulse 80-100, irregular, intermitting; respiration very peculiar; patient would breathe quietly for three or four minutes, then would follow a long, sighing, jerking inspiration, after which all became natural again. Touching his hand rather suddenly for the purpose of feeling his pulse, caused a shuddering of the whole body with spasmodic action of the muscles of the neck, during which the stermo-mastoidei appeared very prominent. The same effect was produced by speaking to him suddenly, by the approach of any one to the bed-side, or on his attempting to reply to any question. Had swallowed nothing since Sunday evening, every attempt to do so causing spasms. . A tumbler containing water was given to him, with the request that he would drink from it; he took it in his hand and endeavored to bring it to his mouth, but did not succeed. Instead of carrying the tumbler towards his mouth, his hand was forced in the opposite direction, and his head jerked backwards notwithstanding all his exertions, which were so great as to cause the perspiration to start from every part of his body, but especially from his head and neck. There were two cicatrices on the outside of left calf, about midway between knee and ankle, marking the spots where the dog's teeth had entered; each of these would, perhaps, cover the area of a three-cent piece, were rather bluish in color, and covered with a furfuraceous scab. On pinching these spots, patient made no complaint ; linear cicatrices alone remained as the result of the wounds about right ear. It being desirable that the lad should be ignorant that any connection was supposed to exist between the bites made by the dog and his present illness, none but indirect questions on this subject could be put to him.

Patient was not inclined to converse, answering questions as much as possible by motions of the head; no appetite ; great thirst ; complained of a continual sensation of chilliness ; no dejection since Saturday. Ordered $z$ ss. of castor oil in coffee, to be taken in teaspoonful doses; mustard poultices to feet.

5. $\frac{1}{2}$, P.M.-Visited patient with Dr. John Homans ; Dr. W. B. Morris, of Charlestown, was also present, having been called in during my ab- 
sence, and from this time he followed the case with me to its termination. Pulse as before. Has had a good dejection from the oil, after having taken two teaspoonsful. Skin moist, covered with an acid, offensive perspiration. Spasms occurred, without any particular exciting cause, about once in ten minutes; they were of a shivering nature, and lasted about one minute. They were excited by the slightest touch, the sudden approach of a person to the bed-side, the sight of a lainp, or by a current of air, but not by the noise of liquid poured from one vessel into another. The approach of liquids to his lips was especially disayreeable to the lad, causing a jerking backwards of the head and a suffocative feeling in the throat. No increase of saliva. During the intervals of paroxysms, respiration was tolerably easy, though always hurried; expression of countenance anxious, frightened; manner nervous, agitated; answered questions correctly, and was rather more inclined to talk. Ordered brandy, one part to two parts of water, a tablespoonfiul to be given every half hour, and oftener if possible.

12, P.M.-Spasms were more frequent and distressing. Patient was able to take warm liquids $3 \mathbf{j}$. at a time, but with great suffering. In giving him anything to drink, it was necessary to carry the spoon slowly towardis his mouth, which always caused a spasm as above stated. After a moment he was able to open his mouth slightly, when the spoon was quickly thrust in by the attendant, and its contents swallowed with a sudden snapping motion of the jaws; this was followed by jerking of the head backwards and difficulty of respiration for a minute or so. If the spoon was presented to him suddenly, he said, "Don't! you frighten me! Oh dear! I wish I wasn't so fidgety," \&c. Brandyand water had been given to him at short intervals, but the odor being disagreeable to him, whiskey was substituted. The paroxysms became more frequent and violent, but the mental faculties were almost preternaturally clear, the lad frequently asking the nature of his complaint, the cause of the profuse perspiration, \&c., and expressing great willingness to take anything which would " make him any better."

Tuesday, Feb. 28.-At 121, A.M., the inhalation of ether was attempted, but the approach of the saturated sponge causing frightful convulsions, it was abandoned for chloroform, which, however, we were obliged to lay aside for the same reason. He violently resisted these two remedies, would not suffer the sponge or handkerchief to come near his face, and exacted a promise that the attempt should not be made again. Spitting of thin mucus commenced at this time.

At 1, A.M., thirty-five drops of laudanum were administered, and this was repeated about once an hour till 7, A.M., the dose being increased to sixty drops. Cold milk was substituted for whiskey, at patient's earnest request. He slept about twenty minutes twice during the night, but waked both times with a sensation of suffocation. About 2, A.M., expressed a belief that he should die. An hour later, after a short interval of quiet, his pulse became more feeble and rapid, varying from $100-120$; countenance collapsed and very anxious. He suddenly desired that all his family should be roused from their beds in order that he might take leave of them. His request having been complied with, 
he kissed them all, and bade them an affectionate farewell. After a short time, however, his pulse became stronger again, and the spasins returned with increased violence.

Several times during the night he became excited and angry, but afterwards apologized for any hasty expressions he might have used. $\mathrm{He}$ complained constantly of heat and thirst ; once stripped himself entirely naked in consequence of this feeling of heat, and remained so for some time. Was much annoyed by perspiration constantly flowing down his face and neck. Made many heroic efforts to wipe it off, every application of the napkin causing terrible spasmodic action. Restlessness and agitation continued, especially when attempts were made to swallow liquids. At $4 \frac{1}{2}$, A.M., after his second doze, he complained still more of "agony," and expressed regret he had not died after taking leave of his family; said he was perfectly ready and anxious to die. Once, only, during the night did he show any incoberency in his language, and that only in one remark. Once, also, about the same time, he loudly and rather angrily ordered all persons to keep away from the bed-side, as he feared he should have hydrophobia ; a moment afterwards he desired the attendants to return. His sense of hearing was so acute as to be annoyed by a very slight singing noise made by the flame of a small spirit-lamp, of which only one wick was lighted, and standing at a distance from the bed on the mantel. This noise he referred to his own throat, and would not believe it to be elsewhere till the lamp was removed from the chamber. Spitting of thin mucus continued, causing much distress to the patient. I left him at $5 \frac{1}{2}$, A.M., more tranquil, and returning thanks to me for remaining with him during the night; indeed, he was very grateful for every attempt made to alleviate his sufferings.

At 9, A.M., Dr. George Hayward, Sen., visited the patient with me. We found him quite free from spasm, save of a slight nature, and conversing freely with his friends as to what he would do when he got about again. He could take warm liquids from a spoon with a little effort, the spasms being much less severe than in night. Every attempt to swallow cold water, however, continued to be very distressing to the lad, though not to so great a degree as yesterday. He was able to take a tumbler in his hands, and after a few spasmodic efforts he could bring it to his lips and swallow a small quantity of its contents. Pulse 120; skin moist and warm; tongue moist, without any coat. Dr. Hayward asked him what was the matter with him: he replied, "he thought it was a queer sort of disease, a 'nervous fever,' he believed they called it."

I did not see the patient again for two hours, but was told by Dr. Morris, on my return at $11 \frac{1}{2}$ A. M., that a great change for the worse had taken place about half an hour after Dr. Hayward's visit. From that time the lad never had an interval of rest till death released him. His countenance became more anxious; feeling of suffocation increased; pulse more frequent and feeble. Most of the time he was sitting upon the edge of the bed, with his chest exposed opposite an open window, anxious for air; was agitated by and impatient of any one crossing the room between himself and the window. Spitting of frothy viscid mucus constant. Patient would frequently order the window shut, half opened and re-opened widely, impatiently requesting the person doing it to pass before him as rapidly as possi- 
ble. Intellect still remarkably clear. Complained incessantly of his throat and a terrible feeling of distress about his chest, which he was continually beating with his hands. 'Talked much, rapidly and loudly. Said there was something "rolled up like a cigar" sticking endwise in his throat, which prevented his breathing, and which he was continually endeavoring to vomit or spit up. Many times, after spitting almost incessantly for a few minutes, he said "There! I have got it up;" then in a minute again, "No! I have n't !" Was furiously enraged at times by the sight of a crowd of curious spectators in front of his window, in the street; screamed loudly at them to be gone, threatening to throw a bottle at their heads and to wreak vengeance on the boys as soon as he should be well enough to go out. Would get up at times, move rapidly around the room, and return to bed, after a minute or two, of his own accord.* Peppermint tea was given in $3 \mathrm{j}$. doses to allay thirst. Vinegar was proposed as an empirical remedy by some of his friends, and was given once in the dose of Zij., distressing him exceedingly. Mucus expectorated increased continually in quantity and viscidity, the carpet near the bed being pretty well covered with it. Convulsive movements almost constant, and restlessness much increased. Expressed great agony at the obstruction in his throat; wished to vomit, and to be beaten on the back while coughing to help dislodge it; desired his mother and other relatives to be kept out of the ronm in order that their feelings might be spared, and requested that they might be told that he was "only a little sick."

At about a quarter before 2, P. M., patient being nearly pulseless, and his extremities and countenance being quite livid, Dr. John Homans and Dr. Storer of Boston and Dr. Mason of Charlestown being present, together with Dr. Morris and myself, it was decided to use force and cause him to inhale chloroform for the purpose of relieving his agony, which had now become excessive. He was accordingly enveloped in a blanket, after a severe struggle, and at 21, P. M., he breathed his last, while under the influence of this anæsthetic agent.

The autopsy was made on Wednesday, March 1st, at 10 o'clock, A. M., 20 hours after death. Present-Drs. Hodges, C. Ellis, Morris, Mason, Braun and myself.

External appearances.-Greenish discoloration and peculiar livid appearance of the whole surface of chest and abdomen. Lividity about lips strongly marked. Posterior surface of body discolored by settling of blood. Rigidity of limbs excessive. Very offensive odor of commencing decomposition. Cicatrices of bites on leg still of a bluish color, with an induration around them like a nodule in the skin, and covered with a slight furfuraceous scab. Cicatrices about ear nearly disappeared.

Cerebrum.-Meinbranes perfectly normal and not congested. Subarachnoid fluid, clear and normal in quantity. Pacchionian glands not particularly marked. Substance of brain natural in color and free from congestion, but very soft throughout. Distinction between gray and white matter strongly marked. Nothing remarkable about base of brain, medulla oblongata, or origin of cerebro-spinal nerves, save their general softness.

Cerebellum generally quite soft, otherwise normal.

Spinal Cord.-Fat deposited on exterior of dura mater of cord, more over some portions than over others. Ziij.--iv. of clear serous fluid in the spinal subarachnoid space. Consistence firm and natural. Vessels well filled in lower part of cord, empty above.

\footnotetext{
* There were no involuntary evacuations either of urine or fæces.
} 
Thorax.-Old pleuritic adhesions of lower lobe of left lung. Posterior portions of both lungs much congested. Heart well contracted-left ventricle empty; both auricles filled with soft black coagula ; elsewhere, blood generally fluid.

Esophagus, larynx and epiglottis normal ; no congestion. Papillæ at root of tongue well developed. Salivary glands (submaxillary) of both sides, normal, ducts pervious. Stomach well contracted; internal surface marnelonated in pyloric portion; mucous membrane firm and thick, covered with a considerable amount of viscid mucus.

Intestines-small, empty ; large, empty and contracted. Liver firm and healthy. Pancreas nothing abnormal. Bladder contracted. Solar plexus and thoracic ganglia of sympathetic system presented nothing abnormal.

Remarks. - It may be asked why stimulants were not given in greater quantity, or why no other medicines than those mentioned above were administered? The only answer to such an interrogatory is, that everything which was given to the unfortunate patient caused such intense suffering that it seemed absolutely cruel to persist in forcing him to swallow a quantity of articles, in favor of which no argument could be brought forward other than an empirical one. A similar remark would apply to the administration of chloroform or ether; the only time they were tried, they caused such terrible spasms that it was very easy to promise the lad they should not be forced on him again.

As usual in this disease, nothing was found at the autopsy to account for the symptoms. The only remarkable appearances were the rapidity with which decomposition had commenced, and the general softness of the cerebral substance.

It should have been stated before, that at first the boy had some fears of hydrophobia ; but after his wounds had healed, he had apparently thought nothing more about it.

\section{Chauncy Place.}

TRIAL FOR ALLEGED MALPRACTICE.

[Communicated for the Boston Medical and Surgical Journa].]

Messrs. Editors,-I send you an account of a recent trial for malpractice in Norfolk Co. You may dispose of it, or parts of it, as in your judgment may best serve the interests of the profession.

On the 12th day of June, 1853, John Kerr, an Irishman, about 40 years old, while intoxicated, fell from a wagon and broke his left clavicle, obliquely, near the beginning of the outer third. Dr. Perry, of West Medway, was called to take charge of it. It was dressed with Fox's apparatus. The difficulty in keeping the ends of this bone in place is well known, even with a careful patient, much more so with a subject " notoriously careless and impatient." Kerr seemed to think the bone had never been set, because at times there was a displacement. Accordingly, at the end of eight days, he applied to a neighboring physician for advice, who informed him that it could be readily adjusted, but from professional courtesy declined doing anything, unless the attending physician was present. Dr. Perry was ready and willing to do all that was necessary at that time. Nothing was done until the eleventh day; then Bonesetter Sweet, of Providence, R. I., was applied to, and, of 